\title{
Butene skeletal isomerization over H-ferrierite: a TEOM and in situ IR study on the role of carbonaceous deposits and the location of Brønsted acid sites
}

\author{
Sander van Donk, Eveline Bus, Alfred Broersma, Johannes H. Bitter, Krijn P. de Jong* \\ Department of Inorganic Chemistry and Catalysis, Debye Institute, Utrecht University, P.O. Box 80083, 3508 TB Utrecht, The Netherlands
}

Received 8 March 2002; received in revised form 23 May 2002; accepted 28 May 2002

\begin{abstract}
Butene skeletal isomerization over H-ferrierite (H-FER) is monitored in a catalysis set-up including a tapered element oscillating microbalance (TEOM) and using in situ infrared (IR) spectroscopy. For the first time the location and number of vacant Brønsted acid groups sited in the 10, 8, 6, and 5 membered rings (MRs) of the $\mathrm{H}$-ferrierite framework are established as a function of time-on-stream (TOS). By deconvolution of the acid site-band, it is determined that with proceeding reaction the $8 \mathrm{MR}$ channels are blocked and the available micropore volume and Brønsted acidity on the aged $\mathrm{H}$-ferrierite will be primarily located inside the $10 \mathrm{MR}$ channels. When a maximum amount of hydrocarbons is deposited on the catalyst, vacant Brønsted acid sites are still present. Additionally, IR spectroscopy shows that with TOS carbonaceous deposits are slowly converted from hydrogen-rich alkyl-aromatics into hydrogen-poor cyclopenta-fused-alkyl-aromatics, reducing by-product formation and therefore enhancing isobutene selectivity.
\end{abstract}

(C) 2002 Elsevier Science B.V. All rights reserved.

Keywords: n-Butene skeletal isomerization; Isobutene; Ferrierite; H-FER; Carbonaceous deposits; Coke; Oscillating microbalance; Infrared spectroscopy

\section{Introduction}

A growing demand for isobutene as a raw material for methyl-tert-butyl-ether (MTBE), an octane enhancing fuel additive, has brought about large industrial and scientific interest for the skeletal isomerization of linear butenes to isobutene. The zeolite ferrierite in its acidic form $\mathrm{H}$-ferrierite (H-FER) containing 10, 8, 6, and 5 membered rings (MRs) [1] is an exceptionally selective and stable catalyst for this reaction $[2,3]$. The initial isobutene selectivity is

\footnotetext{
* Corresponding author. Tel.: +31-30-2536762; fax: +31-30-2511027.

E-mail address: k.p.dejong@chem.uu.nl (K.P. de Jong).
}

rather poor, but with longer times-on-stream (TOS) very high selectivities and stabilities can be reached. The alteration in catalytic behavior is often associated with a change in the prevailing reaction pathway [4-8]. Evidence for this was provided by Meriaudeau et al. [5], de Jong et al. [6], and Cejka et al. [8] using ${ }^{13} \mathrm{C}$-labelled butenes, demonstrating that over a fresh H-FER scrambling of the ${ }^{13} \mathrm{C}$-label occurred whereas with prolonged TOS hardly any scrambling was observed. This points out that initially isobutene is formed via a non-selective dimerization-cracking pathway while in the long run isobutene is produced via either a monomolecular, pseudo-monomolecular [7] and/or selective dimerization-cracking pathway. Although there is an ongoing debate on which of 
these pathways will be the main route for isobutene production [9-11], it is commonly established that the selective performance of H-FER coincides with the presence of carbonaceous deposits $[4,6,7,12]$. However, the role of these deposits and the importance of the H-FER Brønsted acid sites are not straightforward [9-15] and will be investigated in this study.

To correlate the amount of carbon deposited on H-FER with its catalytic performance in butene skeletal isomerization, a catalysis set-up including a tapered element oscillating microbalance (TEOM) is used. In literature, data on the final amount of carbon deposited on the catalyst as determined by ex situ methods are available $[6,16,17]$. Additionally, the formation of deposits with time has been monitored in conventional microbalances $[4,18]$. In such measurements, however, reactants are not forced to flow through the catalyst bed like in a down-flow fixed bed reactor. Consequently, the relation between the amount of carbonaceous deposits and the catalytic action can not be fully assessed. Chen et al. [19] clearly described the advantages of the application of a TEOM over conventional microbalances by studying the oligomerization of ethene over ZSM-5. Since all properties of a down-flow fixed bed reactor are maintained the TEOM offers the possibility to quantitatively monitor the formation rate and amount of carbonaceous deposits in situ [19-24], hence in real time, providing valuable information with respect to catalysis.

To establish the nature of carbonaceous deposits and the number of Brønsted acid sites and their locations as a function of TOS, in situ infrared (IR) spectroscopy is applied. Zholobenko et al. [14] and Domokos et al. [15] demonstrated for a fresh H-FER that it is possible to deconvolute the band corresponding to Brønsted acidity into separate contributions. In that way, the $\mathrm{OH}$ groups sited at the different locations in the framework were identified. Zholobenko et al. [14] applied computational and experimental techniques (ammonia TPD and accessibility studies) to interpret the IR spectra and reported five peaks that correspond to bridging $\mathrm{OH}$ groups vibrating in (1) the 10 MR channels, (2) the intersections between the 8 MR and 10 MR channels, (3) the 8 MRs, (4) the 6 MRs and (5) the 5 MRs. Domokos et al. [15] could not differentiate between the two different Brønsted acid sites in the $8 \mathrm{MR}$ channels as detected by Zholobenko et al. [14]. However, they were able to distinguish the differently located Brønsted acid sites as a function of the extent of sodium-exchange. In this study, it will be demonstrated for the first time that it is possible to distinguish the differently located Brønsted acid sites in the H-FER structure during butene skeletal isomerization. The relative numbers of the vacant Brønsted acid sites are determined as a function of the amount of carbonaceous deposits. Furthermore, when a maximum amount of coke is deposited on the catalyst the location of the vacant Brønsted acid sites is revealed, thus giving information on the location of the carbonaceous deposits.

Combining the information provided by in situ IR spectroscopy with the TEOM results, an overall image is obtained reflecting the role of carbonaceous deposits and the location and availability of Brønsted acid sites during butene skeletal isomerization over H-FER.

\section{Experimental}

\subsection{Ferrierite}

Commercially available high silicon- $\mathrm{NH}_{4}{ }^{+}$ferrierite (Zeolyst Int. Si/Al 30) was activated in a dry nitrogen flow at $823 \mathrm{~K}$ for $12 \mathrm{~h}$ to obtain the $\mathrm{H}^{+}$-ferrierite. The sample displayed an acid site concentration of $0.53 \mathrm{mmol} \mathrm{g}^{-1}$, as determined by temperature programmed desorption-thermogravic analysis (TPD-TGA) using $n$-propylamine. Nitrogen physisorption/t-plot analysis shows an external surface area of $42 \mathrm{~m}^{2} \mathrm{~g}^{-1}$ and a micropore volume of $0.132 \mathrm{ml} \mathrm{g}^{-1}$.

\subsection{TEOM/catalysis}

The catalytic experiments were performed in a tapered element oscillating microbalance (1500 PMA, Rupprecht \& Pataschnick) in order to monitor the formation of carbonaceous deposits in situ. The design of the TEOM reactor is such that it consists of a packed catalyst bed through which all the reactants are forced to flow. Because of its excellent sensitivity (in the microgram range with a sample amount of $10-100 \mathrm{mg}$ ) and stability, the TEOM reactor provides the possibility to study real-time catalyst deactivation by uptake of carbonaceous deposits while performing catalysis. The functioning of the TEOM is based on the 
relationship between natural frequency $(f)$ of the tapered element holding the catalyst, and its mass $(m)$ :

$m_{2}-m_{1}=K_{0}\left[\left(\frac{1}{f_{2}}\right)^{2}-\left(\frac{1}{f_{1}}\right)^{2}\right]$

where $K_{0}$ is the spring constant for the tapered element used in the experiment and the subscripts 1 and 2 refer to the change of mass and frequency with time. For a detailed description of the TEOM, we refer to Chen et al. [19,21] and Hershkowitz and Madiara [20].

The tapered element was loaded with $53 \mathrm{mg}$ of H-FER particles $(90-150 \mu \mathrm{m})$. Quartz wool was used on top and bottom of the catalyst bed to keep the particles firmly packed. Measurements were performed at $623 \mathrm{~K}$ and 1.3 bar. Mass flow controllers adjusted the incoming gas flows. Reaction products were analyzed on-line using a Shimadzu 17A gas chromatograph with a Chrompack PLOT capillary column (fused silica- $\mathrm{Al}_{2} \mathrm{O}_{3} / \mathrm{KCL}, 50 \mathrm{~m} \times 0.32 \mathrm{~mm}$ ) equipped with a flame ionization detector. Prior to testing the samples were dried in situ in nitrogen at $623 \mathrm{~K}$. All mass changes were corrected for temperature and gas density differences by performing blank runs over inert samples. The weight hourly space velocity (WHSV) was varied from 4 to $27 \mathrm{~g}_{n \text {-butene }} \mathrm{g}_{\mathrm{H}-\mathrm{FER}}{ }^{-1} \mathrm{~h}^{-1}$ by adjusting the pure $n$-butene gas flow (Hoek Loos, 1 -butene, $\geq 99.5 \%)$. Conversion is defined as the molar ratio of all products ( $\neq n$-butene) to all compounds detected. Selectivities are calculated as the molar ratio of a certain product to all products ( $\neq n$-butene).

\subsection{IR spectroscopy}

FT-IR spectra were recorded on a Perkin-Elmer Spectrum One instrument during the skeletal isomerization of $n$-butene at atmospheric pressure and $623 \mathrm{~K}$. The H-FER sample was pressed into a self-supporting wafer of approximately $3 \mathrm{mg}$ and a diameter of $0.5 \mathrm{~cm}$, by applying a pressure of $200 \mathrm{MPa}$. The wafer was placed in an in situ IR cell and heated up to $623 \mathrm{~K}$ in He stream $\left(10 \mathrm{ml} \mathrm{min}^{-1}\right)$ to remove adsorbed water. IR spectra during adsorption and reaction of $n$-butene on the sample were recorded using a $9 \mathrm{ml} \mathrm{min}^{-1}$ $n$-butene/helium flow $\left(P_{n \text {-butene }} / P_{\text {total }}=0.225\right)$. The first $4 \mathrm{~h}$ TOS an MCT detector recorded the spectra at a time interval of $5 \mathrm{~min}$ and during measurements 20 scans $(22 \mathrm{~s})$ were taken. After $4 \mathrm{~h}$ spectra were recorded at a time interval of $5 \mathrm{~h}$ using a MIR-TGS detector (100 scans, $\sim 9 \mathrm{~min}$ ). The spectra were measured in transmission mode from 4000 to $1000 \mathrm{~cm}^{-1}$ $\left(4 \mathrm{~cm}^{-1}\right.$ resolution) and after background subtraction (spectrum of the empty cell) normalized to the overtone lattice vibration of the dried H-FER between 1880 and $1860 \mathrm{~cm}^{-1}(A=0.3)$, which is a good measure of the thickness of the wafer. The $\mathrm{OH}$ stretch region $\left(4000-3000 \mathrm{~cm}^{-1}\right)$ was deconvoluted using the Origin 6.1 software program, assuming Gaussian bandshapes.

Check experiments have been performed taking spectra of H-FER samples, aged ex situ in a normal down-flow fixed bed reactor. For these samples, the trend in the vacancy of Brønsted acid sites is very similar to the results that will be reported here, which confirms the present study to provide representative insight in the number of vacant Brønsted acid sites during $n$-butene reaction.

\section{Results}

\subsection{TEOM/catalysis}

Fig. 1 displays the catalysis results for butene skeletal isomerization over H-FER and the amount of carbonaceous species monitored in situ by the TEOM as a function of TOS. Already with short TOS a large amount of deposits is present on the catalyst, while the catalytic behavior is still liable to significant changes. In Table 1, data are collected to exemplify the numerical changes in carbon uptake and catalytic performance of H-FER with TOS. Initially at $1 \mathrm{~h}$ TOS, the catalyst contains $2.5 \mathrm{wt}$. $\%$ carbon and displays $81 \%$ conversion, however, isobutene selectivity and yield are low, i.e. 20 and 16\%, respectively. In the region around $20 \mathrm{~h}$ TOS, the amount of deposits levels off at $6.4 \mathrm{wt} . \%$ while conversion declines, isobutene selectivity increases and the yield is slightly enhanced. With proceeding reaction the carbon content slowly increases to a final value around $6.8 \mathrm{wt} . \%$ at $300 \mathrm{~h}$ TOS. It is important to note that during this slow weight growth, the $n$-butene conversion largely decreases to a final value of $25 \%$ at $300 \mathrm{~h}$ TOS and isobutene selectivity increases to $87 \%$. Hence, the change in activity and selectivity can not be directly related to the amount of carbonaceous deposits. 


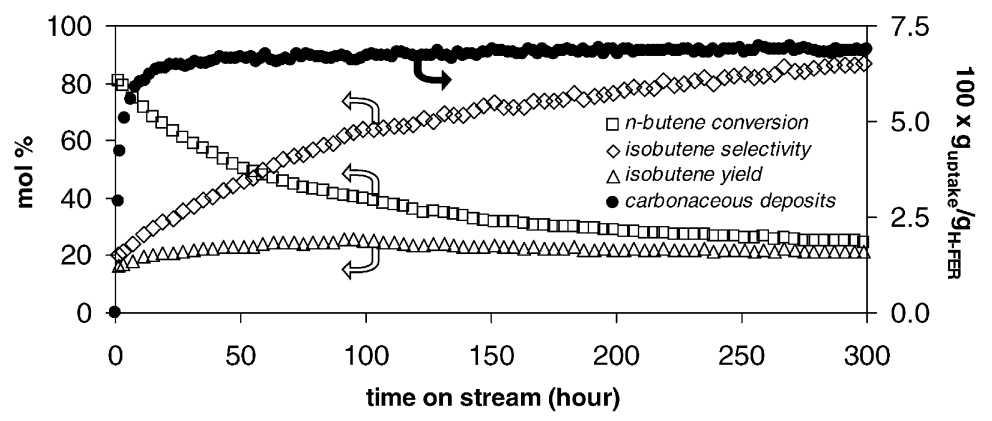

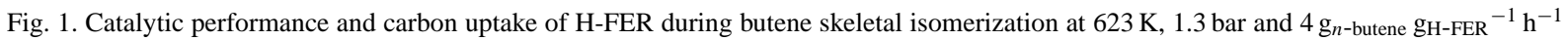
monitored in a TEOM reactor.

Table 1

Effect of TOS on the carbon uptake, $n$-butene conversion, isobutene selectivity and yield during butene skeletal isomerization over H-FER at $623 \mathrm{~K}, 1.3$ bar and $\mathrm{WHSV}=4 \mathrm{~g}_{n \text {-butene }} \mathrm{g}_{\mathrm{H}-\mathrm{FER}}{ }^{-1} \mathrm{~h}^{-1}$

\begin{tabular}{rllll}
\hline TOS $(\mathrm{h})$ & Carbon uptake $($ wt. $\%)$ & Conversion $n \mathrm{C}_{4}=(\mathrm{mol} \%)$ & Selectivity $i \mathrm{C}_{4}=(\mathrm{mol} \%)$ & Yield $i \mathrm{C}_{4}=(\mathrm{mol} \%)$ \\
\hline 1 & 2.5 & 81 & 20 & 16 \\
20 & 6.4 & 65 & 32 & 21 \\
100 & 6.6 & 40 & 64 & 25 \\
300 & 6.8 & 25 & 87 & 22 \\
\hline
\end{tabular}

Due to the opposite trends in conversion and selectivity, the net isobutene yield is almost constant with all TOS, although a shallow maximum is observed around $100 \mathrm{~h}$ TOS.

The carbon content of the final aged H-FER sample is $6.8 \mathrm{wt} . \%$ as monitored by the TEOM. The deposition of carbonaceous deposits reduces the catalyst micropore volume to $0.013 \mathrm{ml} \mathrm{g}^{-1}$ and the external surface area to $19 \mathrm{~m}^{2} \mathrm{~g}^{-1}$. Hence, part of the pores of the aged and selective H-FER catalyst is still accessible for nitrogen. Since the kinetic diameters of nitrogen and $n$-butene are in the same range $[4,6]$, one may assume that up to the same volume is accessible for butene molecules.

Over aged and selective H-FER, i.e. at $300 \mathrm{~h}$ TOS, the WHSV was varied. In theory, this would result in net changes in conversion, selectivity and yield since the rates of the (pseudo)monomolecular and/or bimolecular reactions are different [25]. Fig. 2 shows that increasing the WHSV, thus decreasing the contact time, enhances isobutene selectivity while both conversion and yield are diminished in a similar manner. These results are in good agreement with Byggningsbacka et al. [26].

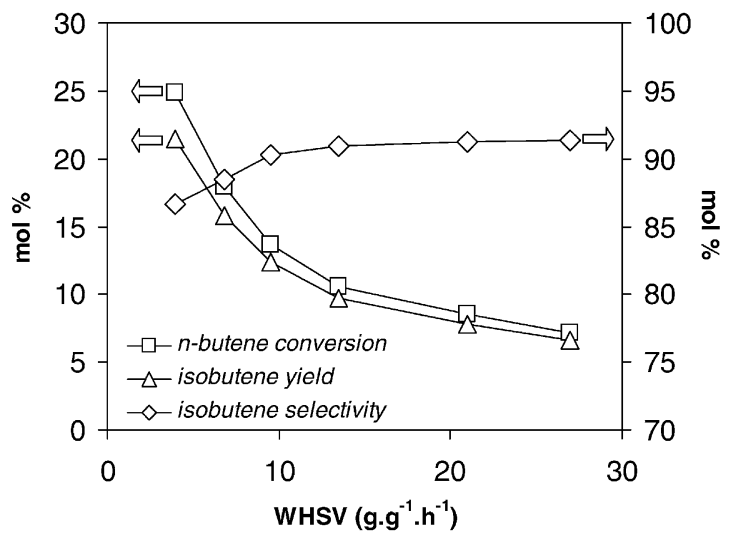

Fig. 2. Conversion, yield and selectivity determined for aged and selective H-FER holding $6.8 \mathrm{wt}$ \% $\mathrm{C}$ at varying WHSVs, $623 \mathrm{~K}$ and 1.3 bar with $P_{n \text {-butene }} / P_{\text {total }}=1$.

\subsection{IR spectroscopy}

In Fig. 3, the IR absorption spectrum of H-FER is shown. An intense band is found at $3580 \mathrm{~cm}^{-1}$, which is assigned to the stretch vibration of the bridging $\mathrm{Si}-\mathrm{OH}-\mathrm{Al}$ hydroxyls, the Brønsted acid sites 


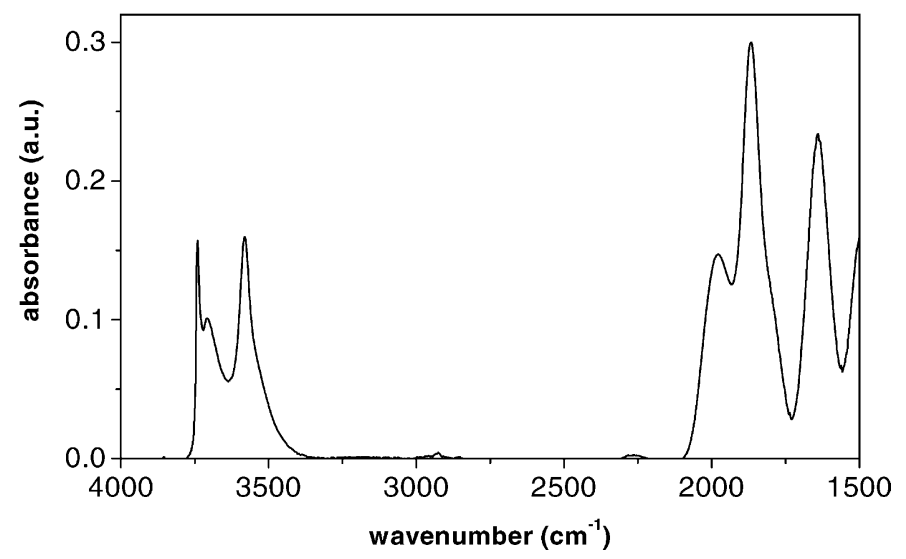

Fig. 3. IR spectrum of H-FER obtained at $T=623 \mathrm{~K}$ under $10 \mathrm{ml} \mathrm{min}^{-1} \mathrm{He}$ flow, after background subtraction (spectrum of the empty cell).

$[14,15,27,28]$. The signal at $3740 \mathrm{~cm}^{-1}$ is assigned to the stretch vibration of the terminal hydroxyls, the silanol groups [14,15,27,28]. An additional band is found at $3700 \mathrm{~cm}^{-1}$, which originates from Lewis acidic non-framework aluminium species [28,29]. In the $2100-1500 \mathrm{~cm}^{-1}$ region, the overtones of the H-FER lattice vibrations are found. Fig. 4 displays the $\mathrm{OH}$ regions of H-FER for the in situ recorded spectra at different TOS. With increasing TOS the total intensity of the $\mathrm{OH}$ band decreases, i.e. the number of acid sites reduces most likely because of irreversible deposition of carbonaceous species. Additionally, a broad band appears around $3300 \mathrm{~cm}^{-1}$, which is assigned to Brønsted $\mathrm{OH}$ groups that are
H-bonded to a $\mathrm{C}=\mathrm{C}$ double bond. This band increases in intensity until $5 \mathrm{~h}$ TOS and then reduces again.

In order to establish the contribution of the $\mathrm{OH}$ sites at different framework positions to the overall Brønsted acid band, the $\mathrm{OH}$ region of the IR spectrum for the fresh H-FER was deconvoluted. An excellent fit was obtained using the set of parameters proposed by Domokos et al. [15], taking into account the difference in experimental conditions. Fig. 5A displays the deconvoluted $\mathrm{OH}$ region of the H-FER spectrum and in Table 2 the matching assignments, peak positions, half-height bandwidths and integrated areas of the peaks are listed. At $3740 \mathrm{~cm}^{-1}$, the band

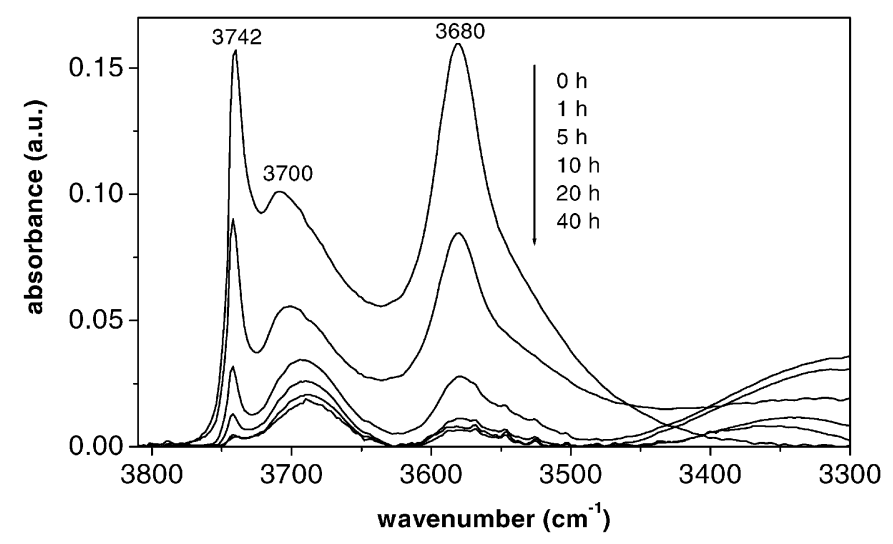

Fig. 4. In situ IR spectra of the $\mathrm{OH}$ region of H-FER without reaction and during $n$-butene reaction at various times-on-stream at $623 \mathrm{~K}$, 1.0 bar and $P_{n \text {-butene }} / P_{\text {total }}=0.225$. 

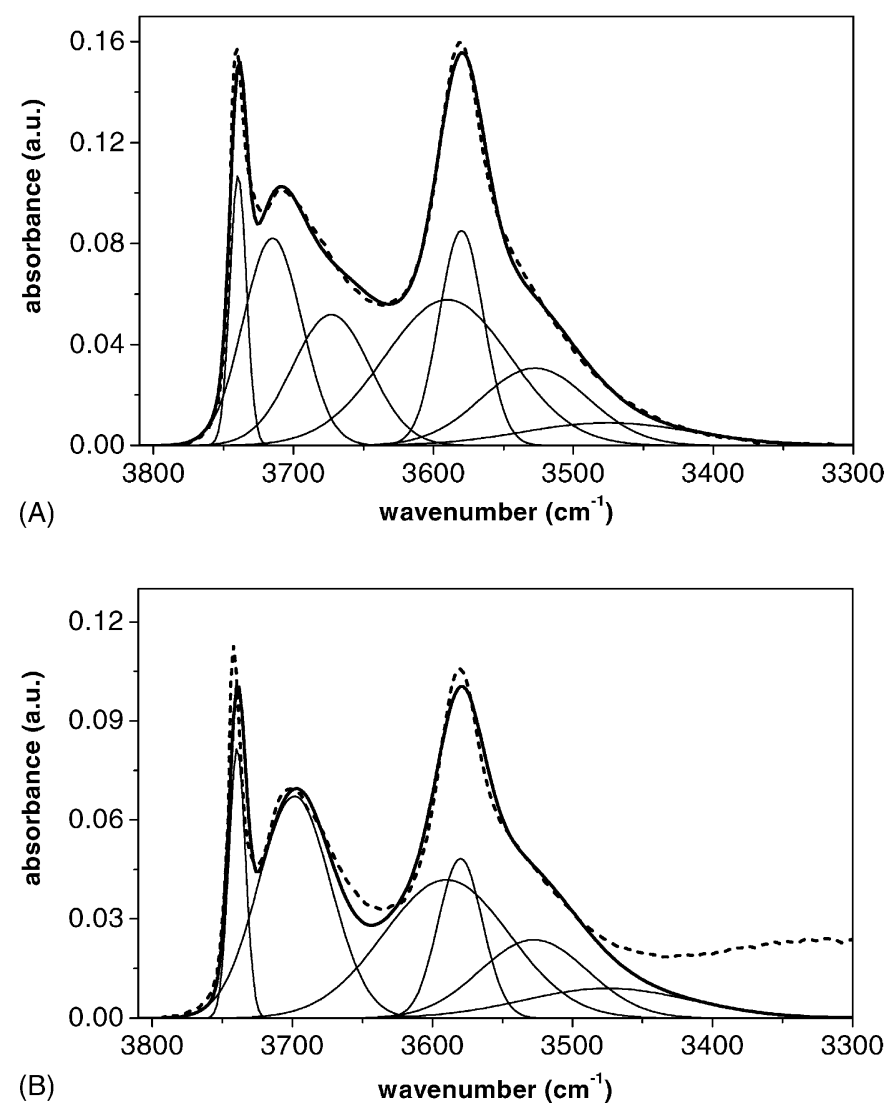

Fig. 5. Deconvolution of the $\mathrm{OH}$ region of the H-FER IR spectrum $\left(T=623 \mathrm{~K}\right.$, under $10 \mathrm{ml} \mathrm{min}^{-1} \mathrm{He}$ flow) -(_.): experimental spectra; (_): computed spectra; (-): single components. (A) fresh H-FER, 0 h TOS. (B) Aged H-FER at $1 \mathrm{~h}$ TOS $\left(P_{n \text {-butene }} / P_{\text {total }}=0.225\right)$.

of the silanol groups is found. The band assigned to non-framework aluminium is composed of two contributions, at 3715 and $3673 \mathrm{~cm}^{-1}$. The band corresponding to the Brønsted acidity is composed of four contributions. The first two bands at 3590 and $3580 \mathrm{~cm}^{-1}$ are assigned to the bridging $\mathrm{OHs}$ in the
10 MR channels, and in the 8 MR channels, respectively. The third band at $3528 \mathrm{~cm}^{-1}$ is assigned to the Brønsted acid sites in the $6 \mathrm{MRs}$, pointing towards the 10 MR channels. The assignment of the band at $3475 \mathrm{~cm}^{-1}$ is ambiguous, but might be attributed to the $\mathrm{OH}$ groups in the 5 MRs $[14,15]$.

Table 2

Parameters for the deconvolution of the $\mathrm{OH}$ region of the spectrum for fresh H-FER as shown in Fig. 5A, bandshapes are assumed to be Gaussian

\begin{tabular}{llcl}
\hline Acid site & Peak position $\left(\mathrm{cm}^{-1}\right)$ & Half-height bandwidth $\left(\mathrm{cm}^{-1}\right)$ & Integrated area \\
\hline Silanol group & 3740 & 11.8 & 1.58 \\
Non-framework aluminum & 3715 & 41.7 & 4.29 \\
Non-framework aluminum & 3673 & 55.1 & 3.58 \\
Brønsted acid sites in 10 MR & 3590 & 90.1 & 6.52 \\
Brønsted acid sites in 8 MR & 3580 & 31.6 & 3.37 \\
Brønsted acid sites in 6 MR & 3528 & 76.7 & 2.94 \\
Probably Brønsted acid sites in 5 MR & 3475 & 119.5 & 1.35 \\
\hline
\end{tabular}



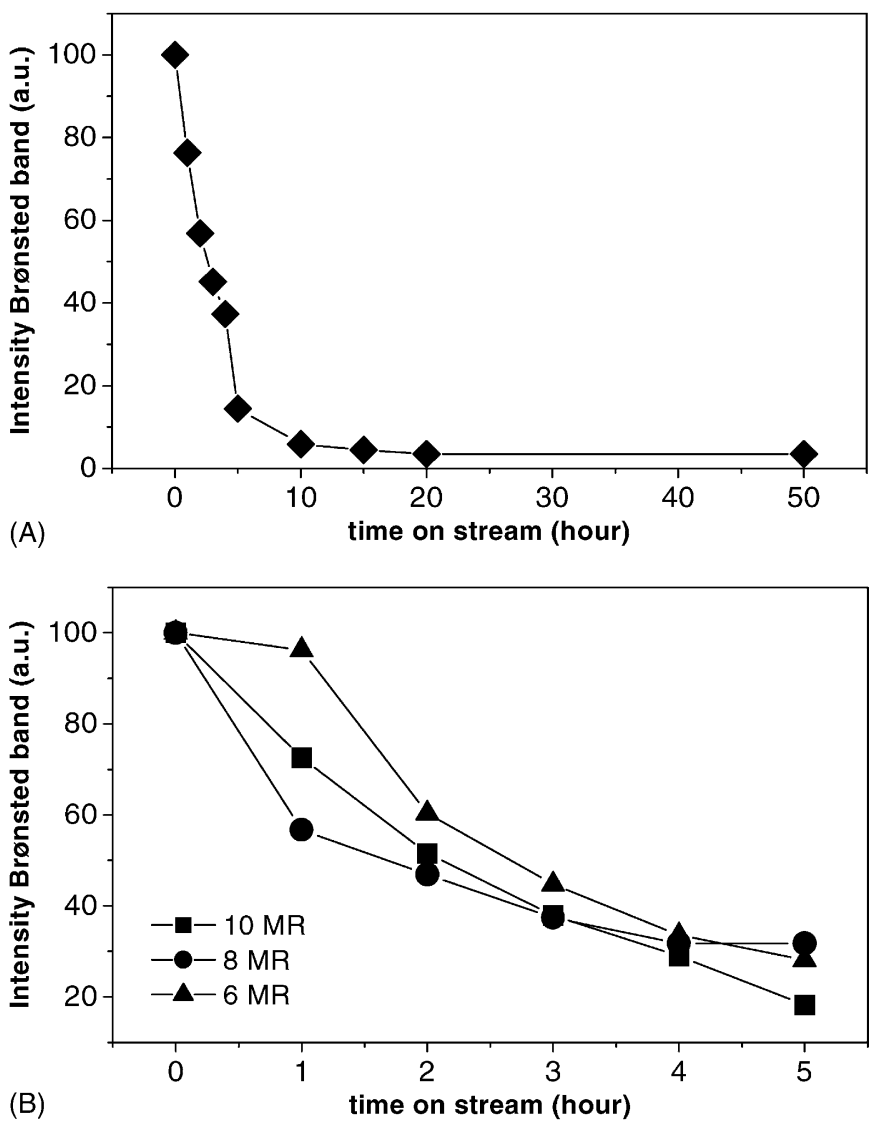

Fig. 6. Number of vacant Brønsted acid sites on H-FER with TOS $\left(T=623 \mathrm{~K}, P_{n \text {-butene }} / P_{\text {total }}=0.225\right)$. (A) Total number, normalized on the number of Brønsted acid sites on fresh H-FER. (B) Number in the 10 MR channels ( $\square$ ), in the 8 MR channels ( ) and in the 6 MRs pointing towards the 10 MR channels $(\mathbf{A})$. The relative numbers of sites are normalized on their respective initial number of sites.

The $\mathrm{OH}$ regions of the spectra obtained with TOS were also deconvoluted such that the peak positions and half-height bandwidths were similar as for the fresh H-FER (Table 2), with exception of the non-framework aluminium bands, which merge into one band at $3698 \mathrm{~cm}^{-1}$. Fig. 5B shows the deconvoluted $\mathrm{OH}$ region after $1 \mathrm{~h}$ TOS. Until $5 \mathrm{~h}$ TOS, the deconvolution resulted in good fits, after that only the total number of Brønsted acid sites could be determined.

All the molar extinction coefficients of the Brønsted acid sites are assumed to be identical [15]. As a consequence, the relative number of vacant Brønsted acid sites in the different channels as a function of TOS can be determined using the results obtained by deconvolution of the $\mathrm{OH}$ regions of the aged H-FER samples.
The total number of Brønsted acid sites as a function of TOS is represented in Fig. 6A. In Fig. 6B, the relative band areas, i.e. the concentrations of the acid sites at the different locations relative to their respective initial concentration are shown as a function of TOS. After $20 \mathrm{~h}$ TOS, there is no significant further change in the number of acid sites. At this stage almost all (97\%) silanol groups have been consumed, while around $15 \%$ of the non-framework aluminium (Lewis acid sites) and 5\% of the Brønsted acid sites are still free (Fig. 4). Combining Fig. 6A and B, it is implied that vacant Brønsted acid sites are still present in the $10 \mathrm{MR}$ channels, in the $8 \mathrm{MR}$ channels and in the 6 MRs pointing towards the 10 MR channels.

The in situ infrared spectra, displaying the region that characterizes carbonaceous species deposited on 


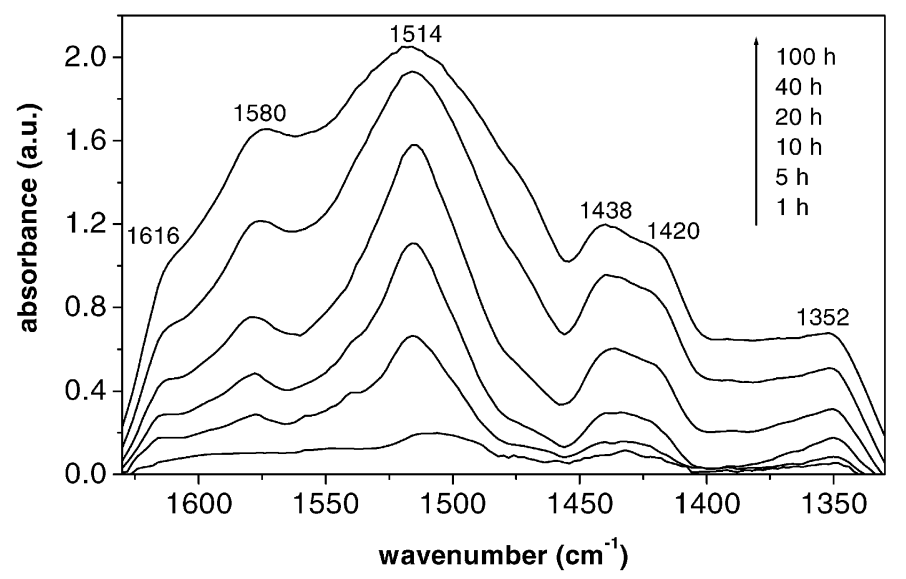

Fig. 7. In situ IR spectra of carbonaceous deposits formed during $n$-butene reaction over H-FER at various times-on-stream at $623 \mathrm{~K}$, 1.0 bar and $P_{n \text {-butene }} / P_{\text {total }}=0.225$. The IR spectrum of the dried H-FER without deposits is subtracted.

H-FER are displayed in Fig. 7. The absorption at $1514 \mathrm{~cm}^{-1}$ corresponds to the carbon-carbon bond vibration of aromatics, at this stage such species are hydrogen rich, i.e. non-condensed [30,31] and already moderately present after $1 \mathrm{~h}$ of exposure to $n$-butene. This band rapidly increases with longer $n$-butene contact. After few hours, additional signals around and 1580 and $1616 \mathrm{~cm}^{-1}$ appear that in combination with the band at $1514 \mathrm{~cm}^{-1}$ indicate the presence of hydrogen-poor carbonaceous deposits [30,31]. Moreover, the peak around $1420 \mathrm{~cm}^{-1}$ indicates the presence of cyclopentane ring structures attached to aromatics. Also two contributions can be distinguished at 1438 and $1352 \mathrm{~cm}^{-1}$, induced by the bending modes of $\mathrm{CH}_{2}$ - and $\mathrm{CH}_{3}$-aliphatic groups, respectively [30-32]. Combination of these results suggests that with prolonged TOS cyclopenta-fused-aromatic ring structures with alkyl-groups are present on the catalyst, as was also demonstrated by Andy et al. [30].

\section{Discussion}

\subsection{On the location of the Brønsted acid sites}

Fig. 1 and Table 1 demonstrate that the skeletal isomerization of $n$-butene over H-FER is accompanied by the formation of large amounts of carbonaceous deposits. Combining the results of Figs. 1, 4 and 7, it is clear that the initial deposition of carbon lowers the amount of Brønsted acid sites, resulting in a decrease of the overall $n$-butene conversion. The enhancement in isobutene selectivity shows that the conversion-drop is due to a suppression of non-selective dimerization-cracking reactions, which dominate the catalytic action with short TOS $[5,6,8]$.

With respect to the alteration in the catalytic performance, discussion is focused on the role of carbonaceous deposits and the importance of the Brønsted acid sites and their locations [9-15]. Concerning this last aspect, this study demonstrates for the first time that deconvolution of spectra recorded in situ, thus during $n$-butene reaction, resulted in good fits (Fig. 5B) using the set of parameters obtained for fresh H-FER (Fig. 5A and Table 2). In this way, the contributions of the silanol groups, the non-framework aluminum and the different Brønsted acid sites have been distinguished, in good agreement with Domokos et al. [15]. Brønsted acid sites in the 10 MR channels, in the 8 MR channels, in the 6 MRs pointing towards the 10 MR channels and those that are assumed to be in the 5 MRs, are identified. Figs. 4 and 6A indicate that with short TOS there is a reduction in the overall number of Brønsted acid sites. Fig. 6B shows that in the first $3 \mathrm{~h}$ TOS, a fast decrease of the sites in the $8 \mathrm{MR}$ channels occurs. This agrees with nitrogen physisorption results [12] that revealed that with low coke content (short TOS) there is a fast decrease in micropore 
volume attributed to a blockage of the $8 \mathrm{MR}$ channels. As a result of such pore blocking effects not all the Brønsted acid sites in the $8 \mathrm{MR}$ channels are consumed, hence there are still vacant sites present but most likely not accessible for $n$-butene. At the same time, Fig. 6B shows that the acid sites located in the 10 MR channels and 6 MRs are deactivated at a lower rate. This again correlates with nitrogen physisorption results [12] showing that there is a slow linear decrease in micropore volume with higher coke contents, i.e. with longer TOS.

The TEOM results in Fig. 1 show that the amount of deposits on H-FER levels off around $20 \mathrm{~h}$ TOS. From the IR results in Fig. 6A, it is clear that after $20 \mathrm{~h}$ TOS no large changes in the total number of vacant Brønsted acid sites are observed. Furthermore, Fig. 4 reveals that when a maximum amount of deposits is present on the catalyst, almost all silanol groups are consumed, although some non-framework aluminum is still available. In the end, the catalyst micropore volume is $0.013 \mathrm{ml} \mathrm{g}^{-1}$ indicating that part of the pores of the selectively operating catalyst is still accessible. Combining Fig. 6A and B it is suggested that at this stage vacant Brønsted acid sites are still present in the 10 MR channels, the 6 MRs pointing towards the $10 \mathrm{MR}$ channels and in the 8 MR channels. Although it seems likely that the latter sites are inaccessible for the reactant when carbonaceous deposits are present on the catalyst, which implies that the available micropore volume and Brønsted acid sites will be mainly located inside the 10 MR channels. Domokos et al. [15] reported on the correlation between acid site locations in sodium-exchanged H-FER samples and their catalytic performance. A clear structure-activity relationship was observed between the Brønsted acid sites located in the 10 MR channels and the selective formation of isobutene. This agrees very well with the results reported in this study and with studies by other groups, implying that the $10 \mathrm{MR}$ channels provide shape selectivity towards the formation of isobutene $[7,13,33]$.

In the future, the accessibility of acid sites on aged H-FER catalysts will be further investigated using $\mathrm{d}_{3}$-acetonitrile, which has proven to be a highly suitable probe molecule for the investigation of the accessibility of acid sites in H-FER with IR spectroscopy [34].

\subsection{On the role of carbonaceous deposits}

After the initially fast deposition of carbon, the TEOM results in Fig. 1 and Table 1 reveal that with proceeding reaction a very slow increase in the amount of deposits from $6.4 \mathrm{wt} . \%$ at $20 \mathrm{~h}$ TOS to a final value of $6.8 \mathrm{wt} . \%$ takes place. Fig. 7 indicates that in the beginning the deposits mainly consist of hydrogen rich alkyl-aromatic compounds. This suggests that at this stage, i.e. when carbonaceous deposits block large part of the acid sites, butene reaction with these alkyl-aromatic deposits and subsequent cracking is the origin of smaller amounts of by-products. Simultaneously with the slow growth in carbon content of H-FER, a relatively large decline in $n$-butene conversion occurs. Additionally, isobutene selectivity is enhanced, which indicates that parallel to the reactions running over the deposits a selectively operating isomerization pathway becomes prevailing.

The variations in conversions and selectivity coincide with a change in the nature of carbonaceous deposits as displayed in Fig. 7, revealing that the initially present hydrogen rich alkyl-aromatic species are slowly converted into hydrogen-poor cyclopenta-fused-aromatic ring structures, which is in agreement with observations by Andy et al. [30]. These species are much less reactive resulting in less reaction with butenes, which mainly lead to by-product formation. Accordingly, a further enhancement in isobutene selectivity with prolonged TOS is induced.

Over the aged and selective operating H-FER catalyst, the WHSV has been varied. Based on the results presented in Fig. 2, it is suggested that the conversion-drop observed with increasing WHSV, can be ascribed to a reduction of non-selective reactions running over the deposits and/or Brønsted acid sites. Consequently, by-product formation but also part of the isobutene production is reduced. This last aspect induces the simultaneous decrease in isobutene yield although it is clear that with prolonged TOS larger part of the isobutene will be formed via a selectively operating reaction pathway. Therefore, the slight selectivity enhancement observed by raising the WHSV, is explained by the increase of the ratio of the selective over the non-selective operating pathway(s). From this it is inferred that both secondary, i.e. bimolecular reactions over Brønsted sites and/or 
reactions running over the deposits, as well as primary reactions may lead to the overall production of isobutene. Although it is evident that the latter reaction pathway displays much higher selectivity and is prevailing with prolonged TOS.

Overall, it is revealed that at prolonged TOS a selective isomerization pathway directly producing isobutene from $n$-butene is operating over an aged H-FER catalyst, containing $6.8 \mathrm{wt} . \%$ of condensed aromatic deposits. The selective operation of H-FER coincides with the availability of some micropore volume and Brønsted acid sites, which will be mainly located inside the $10 \mathrm{MR}$ channels. The present study can not completely clarify whether the latter sites are directly involved in the catalytic action, although it is evident that the sites for isobutene production over aged and selective H-FER are not very liable to deactivation, since very high lifetimes have been reported $[3,6]$.

\section{Conclusions}

Monitoring butene skeletal isomerization over $\mathrm{H}$ FER in a catalysis set-up including a TEOM proves that large amounts of carbonaceous deposits are already present with short TOS. In combination with in situ IR spectroscopy it is inferred that initial deposition of butenes lowers the amount of Brønsted acid sites, suppressing non-selective dimerization-cracking reactions and therefore decreasing the overall activity. Deconvolution of the IR acid band establishes for the first time the number of vacant Brønsted acid sites at different locations in the H-FER framework as a function of TOS. Four types of Brønsted $\mathrm{OH}$ groups located in 10, 8, 6 and 5 MRs can be distinguished. With initial $n$-butene reaction, the 8 MR channels are rapidly blocked and the available micropore volume and Brønsted acidity on the aged H-FER will be primarily located inside the $10 \mathrm{MR}$ channels. With proceeding TOS, when the amount of carbonaceous deposits is stabilized, butene reaction with these deposits and subsequent cracking is the origin of smaller amounts of by-products. IR spectroscopy indicates the deposits to be slowly converted into hydrogen-poor coke, reducing reactivity and concomitant appearance of by-product formation. In the end, isobutene will be produced via a selectively operating reaction path- way over a stable H-FER catalyst holding 6.8 wt.\% deposits.

\section{Acknowledgements}

We thank Tom Visser and Frank de Groot (Utrecht University) for their contributions. This work was financially supported by the Netherlands Organisation for Scientific Research (NWO/CW 700-97-019).

\section{References}

[1] R.E. Morris, S.J. Weigel, N.J. Henson, L.M. Bull, M.T. Janicke, B.F. Chmelka, A.K. Cheetham, J. Am. Chem. Soc. 116 (1994) 11894.

[2] P. Grandvallet, K.P. de Jong, H.H. Mooiweer, A.G.T.G. Kortbeek, B. Kraushaar-Czarnetzki, European Patent No. 501 577 (1992), to Shell.

[3] H.H. Mooiweer, K.P. de Jong, B. Kraushaar-Czarnetzki, W.H.J. Stork, S.C. Krutzen, Stud. Surf. Sci. Catal. 84 (1994) 2327.

[4] W.-Q. Xu, Y.-G. Yin, S.L. Suib, C.-L. O' Young, J. Phys. Chem. 99 (1995) 758.

[5] P. Meriaudeau, R. Bacaud, L.N. Hung, T.A. Vu, J. Mol. Catal. A 110 (1996) L177.

[6] K.P. de Jong, H.H. Mooiweer, J.G. Buglass, P.K. Maarsen, Stud. Surf. Sci. Catal. 111 (1997) 127.

[7] M. Guisnet, P. Andy, N.S. Gnep, C. Travers, E. Benazzi, Stud. Surf. Sci. Catal. 105 (1997) 1365.

[8] J. Cejka, B. Wichterlova, P. Sarv, Appl. Catal. A Gen. 179 (1999) 217.

[9] J. Houzvicka, V. Ponec, Ind. Eng. Chem. Res. 36 (1997) 1424.

[10] M. Guisnet, P. Andy, N.S. Gnep, C. Travers, E. Benazzi, Ind. Eng. Chem. Res. 37 (1998) 300.

[11] J. Houzvicka, V. Ponec, Ind. Eng. Chem. Res. 37 (1998) 303.

[12] S. van Donk, J.H. Bitter, K.P. de Jong, Appl. Catal. A Gen. 212 (2001) 97.

[13] P. Mériaudeau, T.A. Vu, L.N. Hung, G. Szabo, J. Catal. 169 (1997) 397.

[14] V.L. Zholobenko, D.B. Lukyanov, J. Dwyer, W.J. Smith, J. Phys. Chem. 102 (1998) 2715.

[15] L. Domokos, L. Lefferts, K. Seshan, J.A. Lercher, J. Mol. Catal. A Chem. 162 (2000) 147.

[16] G. Seo, H.S. Jeong, D.-L. Jang, D.L. Cho, S.B. Hong, Catal. Lett. 41 (1996) 189.

[17] G.N. Brascó, R.A. Comelli, Catal. Lett. 71 (2001) 111.

[18] M. Guisnet, P. Andy, Y. Boucheffa, N.S. Gnep, C. Travers, E. Benazzi, Catal. Lett. 50 (1998) 159.

[19] D. Chen, A. Gronvold, H.P. Rebo, K. Moljord, A. Holmen, Appl. Catal. A Gen. 137 (1996) L1.

[20] F. Hershkowitz, P.D. Madiara, Ind. Eng. Chem. Res. 32 (1993) 2969. 
[21] D. Chen, H.P. Rebo, K. Moljord, A. Holmen, Chem. Eng. Sci. 51 (1996) 2687.

[22] K. Liu, S.C. Fung, T.C. Ho, D.S. Rumschitzki, J. Catal. 169 (1997) 455.

[23] L.M. Petkovic, G. Larsen, Ind. Eng. Chem. Res. 38 (1999) 1822.

[24] L.M. Petkovic, G. Larsen, J. Catal. 191 (2000) 1.

[25] L. Domokos, L. Lefferts, K. Seshan, J.A. Lercher, J. Catal. 197 (2001) 68.

[26] R. Byggningsbacka, N. Kumar, L.-E. Lindfors, J. Catal. 178 (1998) 611.

[27] W.-Q. Xu, Y.-G. Yin, S.L. Suib, J.C. Edwards, C.-L. O' Young, J. Catal. 163 (1996) 232.
[28] M. Trombetta, G. Busca, S. Rossini, V. Piccoli, U. Cornaro, A. Guerci, R. Catani, R.J. Wiley, J. Catal. 179 (1998) 581.

[29] Y.S. Yin, A. Auroux, J.C. Vedrine, Appl. Catal. 37 (1988) 1.

[30] P. Andy, N.S. Gnep, M. Guisnet, E. Benazzi, C. Travers, J. Catal. 173 (1998) 322.

[31] Z.R. Finelli, C.A. Querini, N.S. Figoli, R.A. Comelli, Appl. Catal. A Gen. 187 (1999) 115.

[32] C. Pazè, B. Sazak, A. Zecchina, J. Dwyer, J. Phys. Chem. B 103 (1999) 9978.

[33] J. Houzvicka, S. Hansildaar, V. Ponec, J. Catal. 167 (1997) 173.

[34] C. Pazè, A. Zecchina, S. Spera, G. Spano, F. Rivetti, Phys. Chem. Chem. Phys. 2 (2000) 5756. 